\title{
PRIMARY NONKERATINIZING SQUAMOUS CARCINOMA OF BREAST WITH IPSILATERAL AXILLARY LYMPH NODE METASTASIS: A CASE REPORT
}

\author{
Amoolya Bhat ${ }^{1}$, Vijaya $C^{2}$, Geethamani V ${ }^{3}$, Gurappa V. Pyatigoudar ${ }^{4}$, Archana C. Shetty ${ }^{5}$
}

\section{HOW TO CITE THIS ARTICLE:}

Amoolya Bhat, Vijaya C, Geethamani V, Gurappa V. Pyatigoudar, Archana C. Shetty. "Primary Nonkeratinizing Squamous Carcinoma of Breast with Ipsilateral Axillary Lymph Node Metastasis: A Case Report". Journal of Evolution of Medical and Dental Sciences 2014; Vol. 3, Issue 16, April 21; Page: 4373-4377,

DOI: $10.14260 /$ jemds/2014/2445

ABSTRACT: Primary squamous carcinoma is a rare type of metaplastic carcinoma of the breast, incidence being less than $0.1 \%$ of all breast carcinomas. The non-keratinizing variant can mimic several rare types of breast carcinomas, prognosis and therapeutic modalities of which are dissimilar. Histopathological examination is gold standard in diagnosing these tumors. Accurate diagnosis employing special stains and immunohistochemistry is mandatory as they are triple negative unlike infiltrating ductal carcinoma NOS, and have aggressive course, poor prognosis and distinctive treatment modalities. Other unique features include less frequent axillary nodal metastasis and necessity to rule out metastatic squamous carcinomas to the breast from other primary sites in these patients. We present a 60 years old lady with a hard lump in the left breast, with no significant past history. Physical examination was suggestive of carcinoma of breast with axillary lymphadenopathy. Histopathological examination revealed squamous carcinoma of breast positive for p63 and cytokeratin (CK) 5/6. Her chest X-ray, abdominal ultrasonography, oral cavity, laryngobronchoscopy, cystoscopy and cervical Pap smears were unremarkable ruling out the possibility of primary squamous tumor in other common organs.

KEYWORDS: Metaplastic carcinoma, non-keratinizing, primary squamous carcinoma, squamous carcinoma of breast.

INTRODUCTION: The incidences of primary squamous carcinoma of the breast vary between $0.1 \%$ to less than $0.04 \%$ of all breast carcinomas.1-3 'Squamous carcinoma of the breast' refers to a tumor in which more than $90 \%$ of the neoplastic cells are squamous. 'Pure squamous' carcinomas show only squamous cells. ${ }^{4}$ The term 'primary squamous carcinoma' of breast is used when the possibility of metastatic squamous carcinoma is ruled out. ${ }^{4}$

Immunohistochemistry and special stains differentiate non-keratinizing squamous carcinoma from its histological mimics. These are very aggressive, treatment refractory tumors with poor prognosis. ${ }^{3}$ The modalities of therapy also vary as they are hormone receptor negative. ${ }^{3}$

CASE REPORT: A 60 years old post-menopausal woman presented with a painless lump in the left breast since 6 months. There was no history of nipple discharge or skin ulceration. There was no significant past history.

Physical examination revealed a hard fixed mass in the upper outer quadrant of left breast measuring $4 \times 3 \mathrm{~cm}$. The nipple was retracted. Fine needle aspiration cytology of the lesion revealed carcinoma of breast (Figure 1b). She underwent modified radical mastectomy with axillary clearance.

Grossly, the tumor measured $4 \times 2.5 \mathrm{~cm}$. The cut surface showed areas of necrosis and cystic change. There were no chondroid or osseous areas. The tumor was completely separate from the adjacent skin, nipple and areola (Figure1a). Six axillary lymph nodes were retrieved. 
Histopathological examination showed an invasive carcinoma composed of sheets of polygonal squamous cells (Figure 2a) having abundant pale granular to clear cytoplasm and distinct cell borders (Figure 2b). Scattered cells showed eosinophilic hyaline cytoplasm (Figure 2c).

The nuclei were round to oval and vesicular with prominent eosinophilic nucleoli. Macronucleoli and multiple nucleoli were also seen (Figure 2d). There were seven-eight mitotic figures/10HPF. Moderate lymphoplasmacytic infiltrate surrounded the tumor nests. Areas of necrosis were present. There was no evidence of squamous pearls or tubule formation.

There was no spindle cell or mesenchymal element. Although adjacent breast tissue showed intraductal and invasive ductal carcinoma NOS type it constituted only six to seven percent of tumor. Four of the six axillary lymph nodes showed metastasis.

Non-keratinizing squamous cell carcinoma, invasive clear cell apocrine carcinoma, glycogen rich carcinoma and sebaceous carcinoma of breast were considered as the differential diagnoses.

The periodic acid-Schiff (PAS) stain was negative ruling out apocrine and glycogen rich carcinomas.

The immunohistochemical analysis using estrogen receptor(ER), progesterone receptor(PR), HER2/neu, p63 and cytokeratin(CK)5/6 showed a triple negative tumor with diffuse nuclear positivity for p63 (Figure3a)and cytoplasmic CK5/6 positivity (Figure3b).

Thus a final diagnosis of metaplastic non-keratinizing squamous cell carcinoma of the breast grade III with ipsilateral axillary lymph node metastasis was made. The patient was further evaluated for excluding metastatic squamous cell carcinoma from more common sites like uterine cervix, lungs and skin etc.

There was no history of cough, hemoptysis, bleeding per vagina, hoarseness of voice, dysphagia, or reddish discoloration of urine. Chest X-ray, abdominal ultrasonography, Pap smear, laryngoscopy, cystoscopy and pharyngo-esphagoscopy were unremarkable, ruling out other primary epidermoid carcinomas in this patient.

DISCUSSION: Primary squamous cell carcinoma of the breast is a rare neoplasm comprising approximately $0.1 \%$ of all the breast carcinomas. ${ }^{1-3}$ Several rare histological subtypes of carcinoma of breast may mimic the non-keratinizing variant of this tumor.

Clear cell invasive apocrine carcinomas of the breast show nests and sheets polygonal cells with abundant foamy cytoplasm round to oval vesicular nuclei and prominent nucleoli. Eosinophilic macronucleoli and lymphoplasmacytic infiltration around the tumor nests has been described.4 They show periodic acid Schiff, cytokeratin, and HER2/neu positivity, ${ }^{4}$ and ER, ${ }^{4}$ PR, ${ }^{4}$ and p63 negativity. ${ }^{5}$

Sebaceous carcinomas of the breast have dual population of cells one with moderate amounts of eosinophilic cytoplasm, another with abundant vacuolated cytoplasm and variably compressed nuclei. Focal squamous morules can be seen in these tumors. ${ }^{4,6}$ They show CK, 6,7 ER, PR positivity ${ }^{6,7}$ and p63 negativity. ${ }^{7}$

Glycogen rich carcinomas display polygonal cells with clear granular cytoplasm, sharply defined borders, hyperchromatic clumped nuclear chromatin and prominent nucleoli.4, 6 The tumor cell cytoplasm contains periodic acid Schiff positive and diastase labile material. ${ }^{4}$

Non-keratinizing squamous carcinomas of the breast show sheets of squamoid cells having abundant cytoplasm, distinct cell borders vesicular round to oval nuclei with prominent nucleoli. Squamous pearls are poorly formed or absent. They are negative for periodic acid Schiff stain and 
show CK5 and $\mathrm{CK}^{8,9}$ positivity. p63 is a sensitive marker for metaplastic carcinomas of the breast especially the squamous type. ${ }^{4}$ The coexpression of both p63 and CK5/6 in more than ten percent of tumor cells has a specificity of 0.96 and a sensitivity of 0.77 for squamous carcinomas. ${ }^{10}$

Squamous carcinoma of the breast has an aggressive course with outcome comparable to poorly differentiated breast adenocarcinoma. ${ }^{3}$ Prognosis of apocrine carcinoma of breast is similar to and that of the glycogen rich and sebaceous carcinoma is worse than invasive ductal carcinomas. ${ }^{6}$

Squamous cell carcinomas in other sites frequently metastasize to regional lymph nodes but the axillary lymph nodal metastases in squamous carcinomas of the breast, is about 10-20 per cent.1,4

The present case showed infiltration in four of six axillary nodes.

Careful and accurate classification of these tumors is necessary as the therapeutic modalities of squamous carcinomas of breast are different from the invasive ductal carcinomas. Estrogen and progesterone receptor negativity,4,6 makes it impossible to use hormonal adjuvant therapy. They are radiosensitive; however local recurrence is common after therapy. ${ }^{1,3}$ Epidermal growth factor receptor (EGFR) antagonists can be used to reduce the loco-regional relapse when epidermal growth factor receptor is positive. ${ }^{1,3}$

CONCLUSIONS: Non-keratinizing squamous carcinoma of the breast is an uncommon entity with various histological mimics thus requiring special stains and immunohistochemistry for histological subtyping of tumor. The squamous carcinoma of breast is unique in that the patients with these tumors must be investigated to rule out metastasis to the breast from another primary site.

Nodal metastasis is rare in squamous cell carcinoma of the breast. However in this case four lymph nodes were involved. These carcinomas result in local relapse following irradiation, and chemotherapy is preferred over hormone therapy. Epidermal growth factor receptor positivity makes it possible to use epidermal growth factor receptor antagonists for therapy.

\section{REFERENCES:}

1. Pramesh CS, Chaturvedi P, Saklani AP, Badwe RA. Squamous cell carcinoma of breast. J Postgrad Med. 2001; 47:270.

2. Flikweert ER, Hofstee M, Liem MSL. Squamous cell carcinoma of the breast: A case report. World Journal of Surgical Oncology. 2008; 6:135.

3. Aparicio I, Martinez A, Hernandez G, Hardisson D, De Santiago J. Squamous cell carcinoma of the breast. Eur J Obstet Gynecol Reprod Biol. 2008; 137:222-6.

4. Rosen PP. Rosen's breast pathology. Philadelphia, PA: Lippincott Williams \& Wilkins; 2009.

5. Ivan D, Nash JW, Prieto VG et al. Use of p63 expression in distinguishing primary and metastatic cutaneous adnexal neoplasms from metastatic adenocarcinoma to skin. J Cutan Pathol. 2007; 34:474-80.

6. Tavassoli FA, Devilee P, editors. World Health Organization classification of Tumors. Pathology and genetics of tumors of the breast and female genital organs. Lyon, France: IARC Press; 2003.

7. Hisaoka M, Takamatsu Y, Hirano Y, Maeda H, Hamada T. Sebaceous carcinoma of the breast: Case report and review of the literature. Virchow's Arch. 2006; 449:484-8.

8. Sassi F, Sarli G, Brunetti B, Morandi F and Benazzi C. Immunohistochemical characterization of mammary squamous cell carcinoma of the dog. J Vet Diagn Invest. 2008; 20:766. 


\section{CASE REPORT}

9. Smedts F, Ramaekers F, Troyanovsky S et al. Keratin expression in cervical cancer. Am J Pathol. 1992; 14:497-511.

10. Kaufmann O, Fietze E, Mengs J, Dietel M. Value of p63 and cytokeratin $5 / 6$ as immunohistochemical markers for the differential diagnosis of poorly differentiated and undifferentiated carcinomas. Am J Clin Pathol. 2001; 116:823-30.

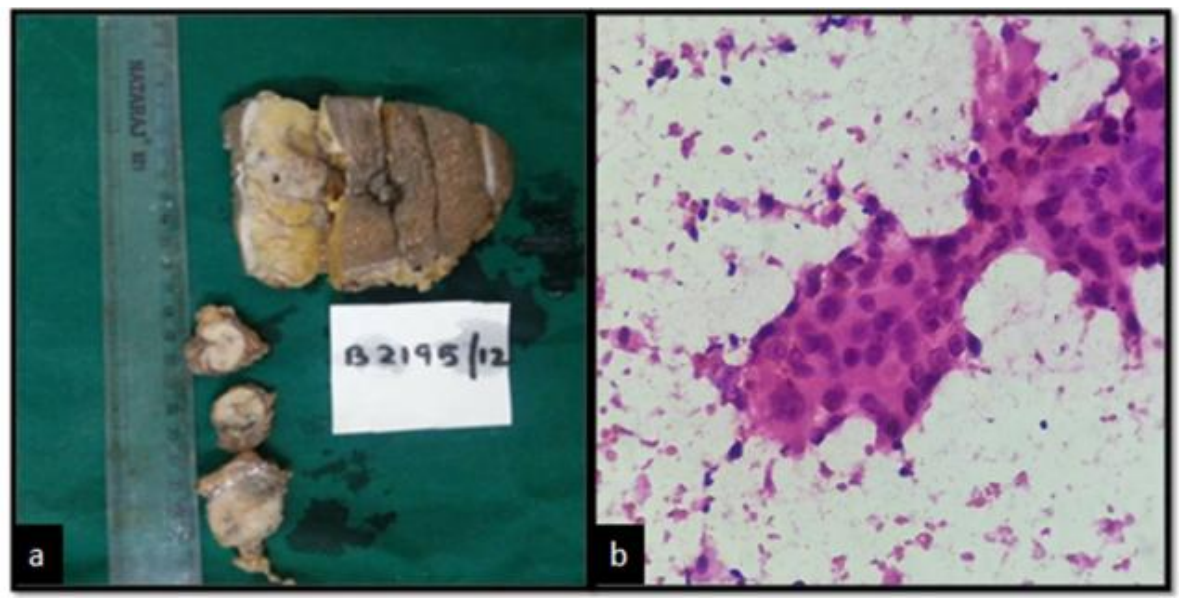

FIG 1: (a) Gross examination showing well defined tumor with variegated cut surface. (b) FNAC smear showing pleomorphic ductal epithelial cells with moderate cytoplasm and intercellular bridges (H and E; $\mathrm{x} 400)$.

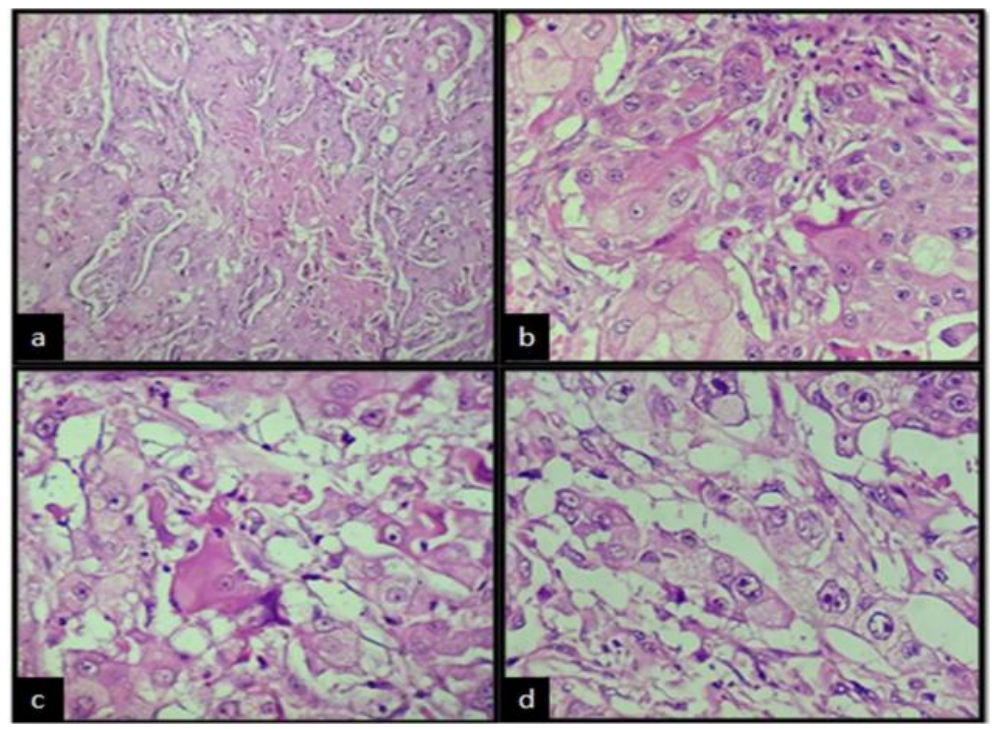

FIG 2: (a)Sheets of polygonal cells and areas of necrosis(H and E;x100); (b)Polygonal cells having distinct cell borders, and abundant granular cytoplasm(H and E;x400); (c)Scattered tumor cells with eosinophilic hyaline cytoplasm(H and E;x400); (d)Cells with vesicular nuclei and macronucleoli(H and E;x400). 


\section{CASE REPORT}

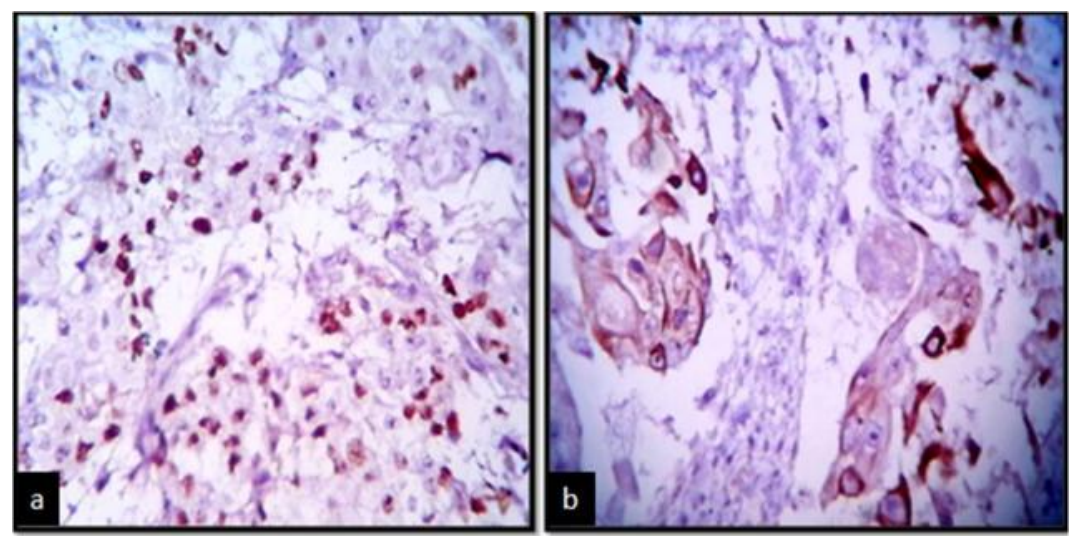

FIG 3: (a) Diffuse nuclear positivity for p63 in the tumor cells (IHC; x400); (b) Cytoplasmic CK5/6 positivity in the tumor cells (IHC; $\mathrm{x} 400$ ).

\section{AUTHORS:}

1. Amoolya Bhat

2. Vijaya $\mathrm{C}$.

3. Geethamani V.

4. Gurappa V. Pyatigoudar

5. Archana C. Shetty

\section{PARTICULARS OF CONTRIBUTORS:}

1. Assistant Professor, Department of Pathology, Sapthagiri Institute of Medical Sciences and Research Centre, Bangalore, Karnataka, India.

2. Professor, Department of Pathology, Sapthagiri Institute of Medical Sciences and Research Centre, Bangalore, Karnataka, India.

3. Professor and HOD, Department of Pathology, Sapthagiri Institute of Medical Sciences and Research Centre, Bangalore, Karnataka, India.

4. Tutor, Department of Pathology, Sapthagiri Institute of Medical Sciences and Research Centre, Bangalore, Karnataka, India.
5. Assistant Professor, Department of Pathology, Sapthagiri Institute of Medical Sciences and Research Centre, Bangalore, Karnataka, India.

\section{NAME ADDRESS EMAIL ID OF THE CORRESPONDING AUTHOR:}

Dr. Amoolya Bhat,

Department of Pathology,

Sapthagiri Institute of Medical Sciences and Research Centre,

\#15, Chikkasandra, Hesaraghatta Main Road, Bangalore - 90, Karnataka, India.

E-mail: amoolyabhat@rediffmail.com

Date of Submission: 19/03/2014.

Date of Peer Review: 20/03/2014.

Date of Acceptance: 28/03/2014.

Date of Publishing: 21/04/2014. 